\title{
OCULAR INJURY CAUSED BY LIQUID AMMONIA*
}

\author{
BY \\ Dr. I. Abramovicz \\ ASSISTANT IN THE UNIVERSITY EYE CLINIC OF PROF. SZYMANSKI, VILNO
}

THE case of ocular injury by ammonia here described is I consider worthy of note on account of the uncommon nature of its origin, the peculiarity of its clinical course, and the comparative rarity of its occurrence (only 23 cases have been recorded between 1841 and 1910 according to Wagenmann).

The patient fainted while his dentist was making the necessary preparations for the extraction of a tooth. The dentist endeavoured to rouse his patient by opening a bottle of ammonia (10 per cent. solution) under his nose. This was done so awkwardly that the contents of the bottle flooded the eyes. The patient had no recollection of the immediate result but consulted Dr. J. Rupp on the following day, owing to the loss of vision. I am indebted to Dr. Rupp for the following account : Both eyelids were red and swollen and glued together with a muco-purulent secretion. The conjunctiva of both eyes was swollen and injected. The right cornea had lost its lustre, but there was no loss of epithelium nor did the iris show any change. The condition of the left eye was distinctly worse. There was some loss of substance in the lower part of the cornea and sclera and the whole cornea was dim. The iris was strongly contracted and injected. Some improvement followed the use of atropin and a weak solution of potassium permanganate, but on the eighth day a sudden increase of the corneal ulceration accompanied by hypopyon and perforation took place. When first seen at the clinic, three weeks after the injury, panophthalmitis had set in and rapidly got worse, so the eye was eviscerated by Professor Szymanski two days later. In the right eye there was only a severe conjunctivitis. Even four months after the original injury the conjunctiva of both eyes was still injected and loose, with considerable warty excrescences, most marked on the left side.

The results observed in this case are in the main in agreement with the experimental work of Pichler, Siegrist, Thies, and Wagenmann on the action of ammonia on the eye.

A ten per cent. solution of ammonia, owing to its power of absorbing water and dissolving albumen, destroys the corneal epithelium and also Bowman's membrane which fuse into a homogeneous, opaque mass. The sudden relapse that occurred a week later was due partly to secondary infection, but also to an invisible and insidious destructive action on the deeper layers of the cornea

*A paper read at a Meeting of the Mediçal Society at Vilno, February 6, 1924. 
as a result of the production of alkali-albumen by the ammonia. It is to be noticed that a 10 per cent. solution of ammonia may produce an intense iritis. The lens seems to have been unaffected.

The following conclusions may be drawn from the above case :

1. Not only pure ammonia gas and concentrated liquid ammonia, but also 10 per cent. solutions may cause severe ocular injury and even, as a result of necrosis, lead to the loss of an eye.

2. That the prognosis in case of ammonia burn should be very guarded since mild original symptoms may later become very serious.

3. This case suggests the inadvisability of the use of ammonia in dealing with cases of fainting.

\section{REFERENCES}

1. Wagenmann.-Graefe-Saemisch Handbuch, Vol. IX. p. 1550, 2nd edition.

2. Thies, O.-Klin. Monatsbl. f. Augenheilk., Vol. LXXII, p. 378, 1924.

3. Siegrist, A.-Zeitschr. f. Augenheilk., Vol. XLIII, 1920.

4. Amman.-Zentralbl, $f$. Augenheilk, 1920.

\section{ANNOTATION}

\section{Congenital Nystagmus}

In a brief note in the British Medical Journal of March 7, Dr. Stenner Evans records an unusual family history of nystagmus. His own patient, a woman, aged 55 years, had marked lateral nystagmus. She informed him that both her father and grandmother (both of whom she remembered well) had always suffered from a similar condition. The patient had six children, five daughters and one son. Of these children, the son suffered from marked nystagmus, but only one of the daughters was slightly affected. The son has one daughter who suffers from nystagmus. Thus nystagmus has appeared in five generations, and is transmitted through both male and female members. One of the male members of the family was a coal miner, and was rejected in 1916 by the recruiting authorities as suffering from miners' nystagmus. Dr. Evans is able to quote another case of congenital nystagmus who had the misfortune, when claiming compensation for miners' nystagmus, to be examined by the same surgeon who had seen him at an early age, before he had ever entered a coal mine, suffering from congenital nystagmus, and had fortunately kept notes of his condition at that period.

Such cases as these above recorded should emphasize the necessity for care in diagnosing miners' nystagmus and awarding compensation solely on movement of the eyes. 